\title{
ÉTICA, ORALIDADE E PESQUISA FOTOGRÁFICA
}

\author{
João Martinho Braga de Mendonça ${ }^{1}$ \\ "Nem sempre sou igual no que digo e escrevo" (F. Pessoa)
}

\section{Introdução}

Rio Tinto fica no litoral norte do estado da Paraíba ${ }^{2}$ (pertence hoje à grande região metropolitana de João Pessoa) e abriga um novo Campus da UFPB, instalado a partir de 2006. O projeto de pesquisa no qual esse artigo se baseia foi submetido em 2009 ao CNPq, para obtenção de apoio através de um edital específico para novos campi universitários ${ }^{3}$. Propõe uma pesquisa exploratória em Antropologia Visual, a qual parte do levantamento de fotografias antigas e de hábitos visuais, com vistas à produção de conhecimentos que se utilizem da imagem e do som, reelaborados com base nas relações estabelecidas com os sujeitos abordados na cidade.

Os primeiros contatos pessoais significativos estabelecidos para a pesquisa foram feitos durante o "Seminário Memória e Imagem no Vale do Mamanguape"4 (entre 6 e 9 de outubro de 2009), quando tivemos convidados locais (inclusive fotógrafos), líderes indígenas e um convidado vindo do Museu Nacional, Prof. José Sérgio Leite Lopes. Nesta ocasião ele apresentou e discutiu seu filme, feito com Rosilene Alvim e Celso Brandão, intitulado Tecido Memória ${ }^{5}$ (sobre trabalhadores das Fábricas de Tecido do município de Paulista-PE) ${ }^{6}$.

\footnotetext{
${ }^{1}$ Universidade Federal da Paraíba, Brasil.

${ }^{2}$ O município de Rio Tinto foi desmembrado da atual cidade vizinha de Mamanguape em 1956, quase quarenta anos depois de surgir como vila operária em função da instalação de uma fábrica de tecidos em terras de engenho de cana, ladeadas por áreas de ocupação indígena (Potiguara). Atualmente conta com uma população de cerca de vinte mil habitantes.

${ }^{3}$ Diversos estudantes têm trabalhado neste projeto, como parte de sua iniciação científica (Antonio Pedro Soares, Danilo Alex Marques de Farias, Luana Maia Pinto, Marianna de Queiroz Araujo, Caio Nobre Lisboa e José Muniz Falcão Neto).

${ }^{4}$ Iniciativa do curso de graduação em antropologia da UFPB/Rio Tinto. Desde 2011 funciona em Rio Tinto e João Pessoa um curso de mestrado em antropologia <www.cchla.ufpb.br/ppga>.

5 Filme documentário premiado em 2010 pela Associação Brasileira de Antropologia <www.abant.org.br>.

${ }^{6}$ Realizamos também visitas de pesquisa na casa de ex-trabalhadores da fábrica de tecidos de Rio Tinto (a qual pertenceu aos mesmos donos da fábrica de Paulista-PE) bem como no casarão construído pelos donos da fábrica, na época em processo de desapropriação pelo governo federal em virtude de estar localizado em atual área indígena.
} 
Através deste primeiro contato com fotógrafos locais e com ex-trabalhadores da fábrica de tecidos ${ }^{7}, \operatorname{logo}$ fui conduzido à Fundação Cultural da cidade onde ficam abrigados os cinco painéis com cento e cinqüenta e três fotografias que foram exibidas na praça central por ocasião do aniversário da cidade em 2006. Foi possível encontrar algumas destas mesmas imagens também disponíveis na internet ${ }^{8}$. A partir destes primeiros contatos e levantamentos procurei seguir as indicações dos fotógrafos e das próprias fotografias para dar sequiência à coleta de imagens e conseqüiente formação de acervo para pesquisas.

Ao longo desse processo diferentes situações e ocorrências foram escolhidas para figurar nas reflexões aqui apresentadas. Trata-se de tentar perceber questões éticas envolvidas nas relações estabelecidas ou observadas a partir de diferentes espaços freqüentados: familiares (privados) e públicos (a partir da cidade ou da universidade). Tentativa que levanta a possibilidade de considerar, nos relatos apresentados, a presença de clivagens provocadas pelos diferentes meios de expressão mobilizados nesta pesquisa: oral, escrito e visual. O texto procura, portanto, transitar entre experiências que dizem respeito mais efetivamente às relações entre "microética" e "mesoética":

(...) correspondendo, a primeira, às esferas das relações face a face que se dão no meio familiar, tribal ou comunitário; a segunda, às relações sociais permeadas pela ação dos Estados (de direito) nacionais por meio das instituições e das leis por eles criadas $(\ldots)$

(Apel apud Cardoso de Oliveira, 2006: 175)

\section{Oralidade: algumas inquietações}

As formas assumidas pelas relações face a face estabelecidas durante a pesquisa levaram às considerações seguintes, as quais procuram esboçar elementos de uma possível caracterização da cultura local no que diz respeito ao lugar ocupado pela

\footnotetext{
${ }^{7}$ A fábrica de tecidos foi inaugurada em 1924, posteriormente tornou-se a "Companhia de Tecidos Rio Tinto", fornecedora das conhecidas "Lojas Pernambucanas" espalhadas em várias cidades brasileiras.

${ }^{8}$ Imagens da festa onde foram exibidas originalmente as fotografias antigas dispostas em painéis de madeira. Disponível em: 〈http://www.riotintopb.com.br/f5read/galeria/galeria.php?varimg=143>. Acesso em 19nov2010. Como também a maior parte das imagens exibidas nos painéis, acompanhadas, desta vez, de mais legendas e detalhes. Disponível em: <http://www.riotintopb.com.br/f5read/galeria/galeria.php?varimg=151>. Acesso em 19 de novembro de 2010. Esta exposição foi produzida pelo Dr. Antonio Luiz (colecionador local) e pelo fotógrafo Hildebrando Domingos. A este último agradeço o apoio e as informações prestadas à pesquisa, como também aos fotógrafos Antonio Fernandes (Toinho) e Ednaldo Félix.
} 
oralidade $^{9}$ nas relações sociais. Embora não sejam fundamentadas em estudos mais detidos (a serem) efetuados na região, procuram ao menos apontar para a importância do tema como forma de questionar os futuros possíveis da relação ética entre a universidade e a cidade ${ }^{10}$.

Os contatos entre populações indígenas (Potiguaras e Tabajaras) e europeias (franceses, ingleses, holandeses e portugueses) na região remontam ao século XVI (Gonçalves, 2007). São conhecidas as histórias de educação de índios (p. ex. Pedro Poty) por holandeses ou portugueses, bem como as cartas redigidas em tupi em 1645, ditadas por índios instruídos junto às missões religiosas (Lima, 1990: 79-104). Vários séculos de colonização, portanto, conformam a incorporação da língua portuguesa pelo povo indígena da região, ao ponto desta ter tomado o lugar da língua materna de seus ancestrais já há mais de um século (Moonen e Maia, 1992: 187).

O processo de aquisição da língua escrita ou alfabetização (no caso da língua portuguesa hoje praticada pelo povo indígena), contudo, é grandemente condicionado pelo acesso à educação formal ${ }^{11}$. Além dos índios que já ocupavam a região, a formação da população de Rio Tinto contou massivamente com sucessivas migrações de famílias camponesas inteiras (analfabetas, em sua maioria) aliciadas para o trabalho na Fábrica de Tecidos a partir de 1920. Estas altas taxas de analfabetismo, constatadas em meados do século XX, motivaram a inclusão do município numa Campanha de Educação Popular (com uso do método de alfabetização de adultos preconizado pelo educador Paulo Freire) do Ministério da Cultura em 1963 (Porto e Lage, 1995: 104).

Tal projeto, contudo, foi interrompido pelo golpe de estado de $1964^{12}$. O acesso às escolas no município não parece ter sido ampliado para parcelas mais amplas de sua população senão nas últimas décadas ${ }^{13}$. Uma das justificativas para a implantação de um campus universitário no município, em 2006, diz respeito justamente a esse tipo de

\footnotetext{
${ }^{9}$ Uma das reflexões que inspira esse artigo foi escrita por Samain (1994). Outro professor, o etnolingüista italiano Maurício Gnerre (autor de Linguagem escrita e poder), também contribuiu, com sua recente palestra no PPGA/UFPB, para os esboços que procuro desenvolver aqui.

${ }^{10}$ Vale lembrar que o Campus IV da UFPB fica no centro da cidade, onde antes funcionava a Fábrica de Tecidos, outrora ativa e central na conformação das relações sociais e atividades culturais locais.

${ }^{11}$ A escola indígena (entre as mais antigas da área) Pedro Poty, localizada na principal aldeia Potiguara (São Francisco) tem pouco mais de dez anos, o que permite deduzir que é relativamente recente o maior acesso à educação escolar e à alfabetização por parte dos índios Potiguara, antes dependentes das escolas urbanas (distantes das aldeias) não diferenciadas.

${ }^{12}$ A história do projeto CEPLAR na Paraíba é relatada no livro de Porto e Lage (1995).

13 Ainda assim, "dados do movimento Todos pela educação mostram que 76,3\% dos alunos que terminaram o ensino médio na Paraíba não aprenderam o conteúdo de português (...)". Jornal Correio da Paraíba, Domingo, 20 de fevereiro de 2011.
} 
demanda, uma vez constatados os baixos índices de desenvolvimento humano (IDH) atribuídos à região.

As considerações seguintes de Antônio Houaiss, generalizadas para todo o Brasil parecem fazer sentido quando penso apressadamente em diferentes amostras de produções escritas de alunos com quem trabalhei nos últimos anos ${ }^{14}$ :

(...) Situação do português no Brasil: ele é praticado como língua natural pela grande maioria da população, que não sabe mais que três mil palavras e com elas se comunica em seu pequeno mundo, desassociando-se de sua cidadania (...) Fala-se, em estatística, que estamos com 30\% de analfabetos. Desafiamos que isso seja verdade. Estamos com $40 \%, 50 \%$ ou $60 \%$ de analfabetos. Analfabetos funcionais, que podem assinar seu nome, mas não lêem um texto ao longo da vida.

(Houaiss, 1986: 11)

O pressuposto principal na passagem acima é de que a ampliação do léxico (verificada com a introdução da escrita) corresponde a um tipo de ganho cultural, o que não reduz a riqueza de uma língua perante outra, mas implica em diferencial nos termos de sua capacidade de transmissão:

(...) Língua por língua, todas as línguas se equivalem; contudo, é visível que, no mundo contemporâneo e no mundo do passado, nunca houve equivalência de línguas. Houve línguas que puderam transmitir poder, que puderam transmitir cultura, que puderam transmitir idéias, que puderam transmitir humanidade, muito mais intensamente que outras línguas. (...) A partir do instante em que a escrita se instituiu, as línguas deixaram de ser línguas morituras, capazes de morrer. Passaram a ser línguas eternizadas. As estatísticas lexicais revelam a diferença das línguas. Há línguas naturais, ágrafas — que ainda existem em grande maioria na Humanidade e nunca apresentam um repertório superior a três mil vocábulos. (...)

(Ibid., p. 2)

A importância aí atribuída à escrita ${ }^{15}$, contudo, não tenderia a diminuir a importância das características próprias do universo da oralidade, as quais permanecem ativas numa sociedade que hoje defende campanhas de inclusão digital (e não mais apenas de alfabetização)? É possível admitir, por exemplo, com Louis Jean Calvet, que "todas as sociedades de tradição escrita conservam uma parte de oralidade, e que essa parte não é, não pode ser considerada como um corpus fóssil.’? (Calvet, 2011: 141)

\footnotetext{
14 Produções escritas repletas de marcas de oralidade e de outras características que demonstram fartamente a inadequação entre o aprendizado da língua escrita experimentado por seus autores e a expectativa (nacional via Ministério da Educação e Cultura) de aprendizado da "norma culta" da língua pelo sistema escolar de ensino fundamental e médio.

${ }^{15}$ Houaiss chega a opor "língua natural" à "língua de cultura". Para o sociolingüista Calvet, no entanto, o problema fundamental (de transmissão da cultura) é resolvido tanto pelas sociedades de tradição oral como pelas de tradição escrita estabelecida, cada qual a seu modo. (Calvet, 2011: 143)
} 
Não será mesmo essa "parte de oralidade" tão viva a ponto de se fazer registrar nos processos de aprendizado da língua escrita e de aparecer, às vezes anos depois, nas produções dos alunos e alunas que chegam ao ensino superior no caso ao qual me referi anteriormente? Poderia a escuta antropológica, em pesquisas qualitativas, revelar algo mais desse universo? Em que medida, ainda por cima, essa "parte de oralidade" se relaciona às formas contemporâneas de visualidade (na fotografia, no cinema, na televisão, no computador, em suma: nas imagens técnicas)? Até que ponto, pois, o universo das imagens técnicas ${ }^{16}$ (sobretudo as digitais, informatizadas) se constitui como um novo aporte para uma noção mais ampliada de cidadania?

A formulação adequada do problema que procuro esboçar aqui precisará de outra ocasião para se fazer mais clara. Basta dizer, por ora, que numa região em que a tradição oral é atravessada por componentes étnicos diferenciados, além de conviver com uma tradição escrita institucionalmente estabelecida há pouco mais de cinqüenta anos, as questões suscitadas pela veiculação e uso de imagens merecem uma atenção e cuidado especiais.

As trajetórias seguidas durante a pesquisa realizada em Rio Tinto trarão elementos para pensar algumas das questões levantadas, bem como para colocar outras. As relações do pesquisador com os diferentes sujeitos encontrados durante a pesquisa serão objeto de uma reflexão incontornável acerca do que representa a instalação de um campus universitário na cidade. Se admito, enfim, que o fundamento do conhecimento a ser produzido é dialógico, como equacionar as formas de relação intersubjetiva postas em prática na pesquisa e seu papel no âmbito de uma reflexão ética mais ampla?

\section{Levantamento de fotografias antigas}

Uma das questões inicialmente trabalhadas, em termos de imagens, foi a de saber como a prática fotográfica se estabeleceu na cidade. Como o município de Rio Tinto emancipou-se em 1956 da cidade vizinha mais antiga (Mamanguape), sendo sua condição de vila operária iniciada em 1924, foi possível descobrir quem foram os primeiros fotógrafos aí efetivamente estabelecidos. Membros de três famílias que residem em Rio Tinto tornaram possível levantar dados sobre a história de vida e o trabalho destes primeiros fotógrafos que atuaram na cidade. Em dois destes casos, a

\footnotetext{
16 A noção de "imagens técnicas" usada aqui é em grande parte tributária dos textos de Vilém Flusser (1985, 2008).
} 
prática fotográfica foi aprendida e continuada, num caso pelo filho (outros filhos também aprenderam o ofício, mas se mudaram) e noutro pelo genro.

Uma primeira expectativa era de que estes fotógrafos continuadores do ofício de seus predecessores guardassem consigo fotografias mais antigas, ainda em preto e branco, relativas à primeira metade do século. Pouco se avançou neste sentido, embora estas famílias tenham guardadas fotografias mais antigas (em geral imagens de poses familiares), não foi constatado um hábito mais definido ou sistemático de colecionamento. As motivações profissionais e comerciais sempre mais imediatas prevaleceram sobre outros tipos de preocupação, sejam relacionados à memória, à paisagem ou mesmo ao registro do próprio trabalho desenvolvido ao longo dos anos.

A partir dos fotógrafos e suas redes de relações seria possível, contudo, chegar aos seus clientes e potenciais colecionadores. Em vista de experiências anteriores conhecidas (Simson, 2007; Eckert e Rocha, 2004) acerca da dificuldade na obtenção de autorizações escritas assinadas para publicação de material fotográfico de pesquisas, procurei a colaboração de um dos fotógrafos da cidade no sentido de que ele disponibilizasse aos seus clientes e amigos uma espécie de ficha (contendo um resumo das intenções do projeto $^{17}$ ) a ser preenchida por quem tivesse interesse. Esse preenchimento identificava o nome, endereço e telefone do colaborador e a maneira como pretendia colaborar (mostrando fotografias guardadas, identificando pessoas ou acontecimentos em fotografias ou contando histórias sobre fotógrafos mais antigos).

O uso da ficha implicava, portanto, em que os potenciais colaboradores lessem e escrevessem seu nome e endereço no papel. O uso da ficha como instrumento de pesquisa foi concebido para atrair clientes (ou amigos) dos fotógrafos e que, obviamente, se interessassem pela fotografia e pelas "histórias" da cidade ${ }^{18}$. Tal procedimento foi experimentado, mas não com exclusividade. Outros tipos de abordagens, em sua maioria presenciais, também se fizeram importantes, senão fundamentais. Opto por enfatizar os resultados obtidos com a "ficha" na medida em que podem ser reveladores no sentido dos questionamentos anteriormente propostos acerca das tradições oral e escrita.

O uso do que estou chamando de ficha tinha como suposição básica o fato de que as fotografias mais antigas e mesmo sua conservação estavam ligadas a um tipo de

\footnotetext{
${ }^{17}$ Basicamente a formação de um acervo de imagens fotográficas da cidade de Rio Tinto acompanhadas de outras informações sobre histórias de vida, acontecimentos importantes, etc. "incluindo aí a história dos fotógrafos (e do cinema) da cidade".

${ }^{18}$ Buscava-se, portanto, perceber uma parte das redes de relações destes fotógrafos.
} 
clivagem social: assim como a escrita, a fotografia foi difundida inicialmente entre uma parcela específica da sociedade, cujo excedente econômico lhes permitia contratar os serviços (inicialmente a custos altos) de fotógrafos. O mesmo excedente econômico também justificava o uso da fotografia como marca de distinção social. Mas o que diversos autores demonstraram em termos da associação entre fotografia e ascensão sócio-econômica burguesa no século XIX, não deixa de fazer ver também outra associação importante: fotografia e urbanização.

Enfim, o pequeno grupo ${ }^{19}$ que, independentemente uns dos outros, preencheu a ficha, era composto por funcionários públicos, em sua maior parte aposentados em cargos mais elevados, e que trabalharam, seja na área do direito, da fiscalização comercial, da política ou da urbanização (empresa de distribuição de água), além de um líder sindical oriundo do quadro de trabalhadores da antiga fábrica de tecidos.

Quase todos mantém fotografias guardadas, as quais dão testemunho de suas trajetórias como membros de famílias locais ou como protagonistas de acontecimentos significativos em termos da história e dos costumes da cidade. As relações travadas com eles permitiram chegar a uma boa parte do acervo de imagens atualmente reunido, mais do que isso, fizeram-me perceber diferentes aspectos ligados à circulação e veiculação de fotografias antigas na cidade, entre os âmbitos privado e público.

O uso de fotografias por eles cedidas para a pesquisa (que segue em andamento) em quaisquer publicações acadêmicas vai implicar, necessariamente, na obtenção de autorizações ou termos de consentimento esclarecido. Acredita-se que a primeira ficha preenchida já constituiu uma espécie de prévia para a introdução de outro tipo de formulário ou termo a ser assinado, ao que a relação de amizade e confiança estabelecida com o tempo tende a tornar tal situação tão pouco constrangedora quanto possível.

Numa sociedade de tradição oral majoritária ${ }^{20}$ as modalidades de inserção do pesquisador se dariam evidentemente de formas diferentes. Mas podemos perguntar se o procedimento adotado (com a ficha) em Rio Tinto tenderia a excluir do universo empírico da pesquisa outros sujeitos que (além de não serem clientes nem amigos dos fotógrafos) guardem fotos, mas que por quaisquer motivações variáveis, não se disporiam a preencher e a assinar uma ficha para um professor do campus universitário?

\footnotetext{
${ }^{19}$ Distribuí 5 fichas para cada um dos três fotógrafos ( 15 ao todo), recebi de volta 5 fichas preenchidas.

${ }^{20}$ Por exemplo, que falasse ainda outra língua (que não o português ou outra língua introduzida em processos coloniais) a qual não estivesse em processo de dicionarização e/ou codificação alfabética.
} 
Tudo leva a pensar que sim, o que demonstra a importância das relações face a face, como forma imprescindível de inserção, numa pesquisa qualitativa.

Passo a relatar alguns desdobramentos desta pesquisa fotográfica de maneira a notar como as fotografias antigas da cidade comportam um valor que constitui objeto de disputas simbólicas. Até que ponto aquilo (em termos de instituições: prefeitura, universidade) que pode ser identificado com a "tradição escrita" tende a reivindicar para si o direito de apropriação destas imagens no âmbito de suas próprias estratégias discursivas? De que maneira essa tendência pode ser percebida pelos sujeitos ao nível de uma microética, nas relações face a face ${ }^{21}$ ?

\section{Redes de relações e circulação das imagens}

Com o tempo foi possível tomar outros contatos, não mais através de fichas preenchidas, mas por indicações diretas de outros sujeitos com quem me encontrava durante a pesquisa de campo (não necessariamente clientes dos fotógrafos). Significa que durante muitos dias fiz um percurso que vai da Universidade (localizada no centro) à praça central e daí ao mercado ou às ruas principais do centro (onde residem colaboradores). Alguns convites (para almoço, festas ou passeios) indicavam-me novas oportunidades bem como os primeiros sinais de maior aceitação da minha presença como pesquisador-professor da universidade.

As poucas pessoas que preencheram a ficha tornaram-se fundamentais para a continuidade da pesquisa e a partir delas e de suas redes de relações pessoais, fui também pessoalmente apresentado a outros potenciais colaboradores. Numa dessas ocasiões encontrei um senhor que se lembrava da ficha oferecida pelo fotógrafo e que afirmou que não quis de modo algum preencher a mesma, mas que se eu quisesse apenas "conversar" era só ir à casa dele que ele adoraria contar as histórias que sabia. Posteriormente, em sua casa, aceitou que fosse gravado seu depoimento acerca da história do cinema em Rio Tinto ${ }^{22}$.

\footnotetext{
${ }^{21}$ Entre familiares, vizinhos e conhecidos.

${ }^{22}$ Gravação dirigida pelo bolsista de iniciação científica (também morador) Danilo Alex Marques de Farias, apresentada no âmbito da disciplina de "Estudos etnográficos" ministrada pela Profa. Silvana Nascimento.
} 
No ambiente de trabalho de Angelo $^{23}$ (um dos colaboradores que preencheu a ficha inicial) conheci outras pessoas e lá diversas vezes retornei para ouvir suas histórias acerca da cidade e perguntar pelas suas fotografias (as quais ele informou que tentaria reunir para me mostrar, já que estavam na casa de seus filhos). Numa dessas vezes ele me mostrou uma pilha de fotografias numa sacola de plástico, as quais haviam sido deixadas lá. Aparentemente, por ser um local de maior circulação de pessoas que pudessem se identificar naquelas imagens.

Percebi a importância do material e pedi a ele a permissão para realizar a digitalização, o que foi feito no mesmo dia sendo-lhe devolvido todo o material no final da tarde ${ }^{24}$. Tratava-se de um conjunto de fotografias colecionadas com diversas cenas de casamentos (casais) e primeira comunhão (crianças), sobre o que Angelo não tinha quaisquer outras informações além do nome da pessoa que tinha ali deixado a sacola com as fotos. Cheguei a voltar lá no horário indicado por Angelo para tentar encontrar a dona da sacola, chamada Carla.

Foi, contudo, num encontro com outro colaborador (também inscrito pela ficha), Alfredo, algumas semanas depois, que fui levado à casa de quem havia deixado a sacola de fotos no ambiente de trabalho de Angelo. A casa de Carla fica a três quarteirões da casa de Alfredo, de onde saímos ${ }^{25}$. Ficou esclarecido que aquelas fotografias de cerimônias haviam sido colecionadas pelo seu irmão, Carlos (já falecido) e ela (Carla) procurava se "desfazer" daquelas imagens, já que eram de pessoas desconhecidas dela ${ }^{26}$ e talvez mesmo de seu irmão.

$\mathrm{Na}$ atitude de Carla estava implicada a idéia de que a imagem pertence à pessoa que nela aparece. Não havia razão, portanto, em manter guardadas fotografias de pessoas que não eram "de casa". Aos poucos, comecei a perceber dinâmicas de circulação de fotografias, dinâmicas nas quais, também aos poucos, me inseri, abrindo a possibilidade do trabalho acadêmico com estas imagens. Isso tornava possível, então,

\footnotetext{
${ }^{23}$ Passarei a usar nomes fictícios (tirados de uma lista de fotógrafos) para desvincular os relatos aqui apresentados dos sujeitos reais com quem tenho trabalhado nesta pesquisa, de maneira a evitar quaisquer constrangimentos desnecessários.

${ }^{24}$ Esse procedimento tem como objetivo estabelecer um padrão de devolução relativamente imediata que permita valorizar a relação de confiança manifestada no ato de cessão das imagens para digitalização.

${ }^{25}$ Em sucessivas visitas, posteriormente desacompanhadas de Alfredo, foi possível criar uma relação de amizade e confiança que nos permitiu conhecer as outras imagens colecionadas por Carlos, então cedidas para digitalização em nossa pesquisa (e imediatamente devolvidas), trabalho que contou com a colaboração da bolsista de iniciação científica Luana Maia Pinto.

${ }^{26}$ Nessa atitude estava implicada a idéia de que a imagem pertence à pessoa que nela aparece; não havia razão, portanto, em manter guardadas fotografias de pessoas que não eram "de casa".
} 
refletir sobre as relações entre a chamada "microética" e a "mesoética", sobretudo a partir do ponto em que pesquisas universitárias tornam-se também publicáveis.

Ao notar a existência de diferentes moradores que colecionam ou colecionaram fotografias (para além dos retratos de família), procurei atentar um pouco mais para o sentido das "práticas culturais" de colecionamento (Gonçalves, 1999: 25). Resta, no entanto, muito ainda a ser feito nas várias frentes de trabalho que se abriram desde então. A formação destas coleções particulares e as trajetórias pregressas dos artefatos fotográficos aí reunidos indicam um campo de relações e disputas a ser esclarecido.

Que tipo de ética preside a passagem de uma (ou mais) fotografia (s) de um sujeito ao outro? Como (oralmente) essa passagem é feita e em que medida oralidade e escrita podem ser equacionadas neste processo $^{27}$ ? Que concepções sobre a natureza da fotografia estão aí implicadas? Em que medida tais práticas de colecionamento expressam hierarquias e relações de poder locais? Como a formação de coleções particulares pode ser relacionada às concepções locais sobre a história do município e seus costumes?

Este conjunto de questões é pensado também a partir de nossa própria pesquisa, a qual propõe a reunião de fotografias (embora digitalizadas) num acervo institucionalizado, viabilizado no campus universitário federal. Vejamos, pois, um pequeno exemplo. Se ao nível de uma micro-ética a fotografia emprestada que não retorna ao seu detentor constitui objeto de uma crítica ou queixa pessoal (afeta, portanto, as relações face a face ao nível local), não será que na esfera meso-ética as implicações da apropriação de fotografias ganham proporções bem maiores, as quais poderiam até mesmo suscitar discussões mais ou menos similares àquelas que tratam, por exemplo, de "repatriamento" 28 , já numa esfera macro-ética?

O valor das fotografias antigas leva, em muitos casos, à criação de acervos institucionais, os quais, no entanto, congregam imagens produzidas pelas próprias instituições, conformadoras de certas visões pertinentes às mesmas (do progresso, do folclore, etc.). O trabalho com fotografias de coleções particulares, mesmo aquelas restritas às fotografias de família, leva a outros tipos de desafios no sentido de perceber as memórias, dinâmicas culturais e histórias de vida de pequenas comunidades, ruas, bairros ou vizinhanças, para além de uma visão “oficial” exclusiva. É o que nos mostra,

\footnotetext{
${ }^{27}$ Em alguns casos, por exemplo, uma fotografia pode ser emprestada em função de alguém que se propõe a escrever um livro.

${ }^{28}$ Ver por exemplo a discussão de Gerard Collomb acerca das fotografias tomadas dos Kalina do Suriname (Collomb, 1998.)
} 
por exemplo, o trabalho de Fernanda Rechenberg sobre circulação de fotografias de famílias negras em Porto Alegre (Rechenberg, 2012).

No município de Rio Tinto, onde ainda não existe um espaço municipal voltado à preservação de fotografias antigas, a pesquisa fotográfica a partir da universidade certamente contribui para que iniciativas nesse sentido sejam tomadas ${ }^{29}$. A exposição fotográfica organizada ${ }^{30}$ em 2006 (referida na introdução), por ocasião do aniversário da cidade, e mantida no espaço da Fundação Cultural pode ser um ponto de partida para a criação de um acervo institucional. As preocupações éticas, contudo, no que diz respeito à circulação, coleção e exposição de fotografias em diferentes espaços e formatos, deveriam presidir quaisquer trabalhos realizados com fotografias no âmbito público.

O acervo reunido durante nossa pesquisa fotográfica realizada em Rio Tinto constitui também uma base, doravante institucionalizada, que servirá para novas pesquisas e produções culturais bem como deverá estar disponível para consultas junto à população local. No entanto, a manutenção destas imagens no acervo e as possibilidades de sua circulação devem, pelo que propõe a pesquisa, estar condicionadas à manutenção das relações inter-pessoais estabelecidas com os sujeitos cedentes das imagens. Estes precisam ser consultados bem como esclarecidos sobre quaisquer usos destas imagens, agora suscetíveis de serem implicadas em relações pertinentes a uma meso-ética ou mesmo a uma macro-ética (de escala planetária).

Em outras palavras, propõe-se que a manutenção e os usos do acervo imagético impliquem diretamente no estreitamento dos laços estabelecidos entre a universidade e os sujeitos que cedem as imagens. Significa, também, que os resultados da pesquisa fotográfica e antropológica podem ser compartilhados, continuamente, através de realizações visuais (vídeos, exposições, etc.) destinadas às escolas e aos espaços culturais do município.

Estas reflexões sobre possibilidades de construção de relações éticas (em diferentes esferas) no levantamento e tratamento das imagens reunidas na pesquisa serão encerradas com alguns exemplos de reações às solicitações de participação e autorização escrita para uso de imagens. Tomarei, pois, a realização do vídeo

\footnotetext{
${ }^{29}$ A atual mudança de gestão municipal aliada aos recursos oriundos de outros âmbitos direcionados para a "cultura" parece fornecer uma conjuntura propícia a esse tipo de trabalho.

${ }^{30}$ Exposição organizada pelo Dr. Antonio Luiz e pelo fotógrafo Hildebrando Domingos. A prática de colecionamento do primeiro tem sido desde o início objeto de nossas reflexões e durante a pesquisa foi possível identificar relações e percursos que compõem a trajetória de alguns dos artefatos fotográficos atualmente sob sua guarda.
} 
documentário intitulado "Passagem e permanência"31 para falar das dificuldades de obtenção dos termos escritos de autorização, a partir das hipóteses anteriormente esboçadas acerca da importância da oralidade.

\section{Participação e consentimento de uso: imagens e vozes editadas}

Primeiramente é preciso dizer que o vídeo foi concebido a partir das imagens reunidas e das relações intersubjetivas estabelecidas. Não havia, pois, um tema ou roteiro previamente estabelecido para o vídeo, eles surgiram durante os encontros e com base nas conversas, solicitações dos sujeitos e imagens levantadas. Dividido em três partes, a primeira e a terceira trazem amostras das coleções particulares (fotografias animadas em seqüências) articuladas aos resultados de práticas de foto-vídeo-elicitação (Banks, 2009) experimentadas. A segunda parte do filme apresenta cenas filmadas durante o desfile de 7 de setembro em Rio Tinto, a partir de um convite de um estudante e morador local.

O objetivo consistiu em mostrar os principais resultados da pesquisa fotográfica em andamento, de maneira a apresentar não apenas uma proposta de valorização das fotografias e da memória coletiva que lhe é pertinente, mas também uma articulação das reflexões suscitadas (pelas próprias imagens) nos sujeitos abordados. Seis pessoas diferentes participaram ${ }^{32}$ (com suas vozes), além da personagem do colecionador (já falecido), que aparece nas falas de seus familiares e dos fotógrafos com quem temos trabalhado. O convite para participação no vídeo foi feito a cada um deles pessoalmente e por escrito, com esclarecimentos sobre a estrutura e os elementos do filme a ser montado.

Uma vez que se tratava de pessoas já nossas conhecidas (ao longo de uma pesquisa que durava quase dois anos) não houve nenhuma objeção ou resistência quanto à participação. Após a montagem do filme cada participante foi convidado a assistir o mesmo numa sessão exclusiva que lhe permitisse expressar suas reações independentemente dos demais participantes. Nessas ocasiões as reações foram gravadas e testemunhadas bem como a resposta à pergunta feita diretamente em termos de terem aprovado ou não a edição realizada a partir dos depoimentos mais longos

\footnotetext{
31 "Passagem e permanência: três ensaios em torno do sete de setembro em Rio Tinto - PB", 18 min, 2012 (selecionado e exibido no IV Festival do Filme Etnográfico de Recife).

32 Tertuliano de Oliveira, Mônica de Souza, Ednaldo Félix, Antonio Fernandes, Hildebrando Domingos e Gabriela Silva (por ordem de aparição no vídeo).
} 
gravados com eles, ou seja, se aprovavam o resultado e se autorizavam sua exibição pública na forma como foram finalmente editados.

Estas sessões e os registros orais constituíram, no entanto, apenas uma prévia para a obtenção de termos escritos do mesmo teor. Não entrarei nos detalhes de algumas reações surgidas durante essa primeira exibição restrita, mas posso dizer seguramente que os participantes, no geral, sentiram-se bastante satisfeitos com o resultado. Isso diz respeito, contudo, à primeira e à terceira parte do filme, compostas de amostras animadas das coleções fotográficas articuladas aos depoimentos motivados pelas mesmas imagens.

A segunda parte do filme, que consiste numa edição, com duração de seis minutos, das filmagens que realizamos no desfile cívico de 7 de setembro de 2011 implicou em outros tipos de autorização, desta vez diretamente solicitados à prefeitura, através de seus representantes.

Primeiramente, antes de filmar, solicitamos ${ }^{33}$ ao coordenador de eventos a autorização para entrar e filmar dentro do cordão de isolamento. Foi-nos oferecida a chance de ocupar até um lugar no palanque montado, posição que, entretanto, não teria contribuído para a visão mais aproximada (e à mesma altura) que busquei dos gestos e movimentos dos participantes das bandas marciais. Em nenhum momento fomos abordados $^{34}$ ou tivemos que comprovar (por escrito) que estávamos autorizados a ficar dentro do cordão de isolamento, ou seja, as autorizações ocorreram oralmente, o coordenador do evento sabia quem éramos e consentia que ocupássemos o mesmo espaço onde circulavam também os fotógrafos.

Ficamos boa parte do tempo fixados (com uma câmera de tamanho médio e um tripé) numa das laterais logo abaixo do palanque, de modo que tínhamos uma visão praticamente frontal das apresentações das bandas ${ }^{35}$. Posteriormente foi solicitada à prefeitura, por escrito, autorização para uso daquelas imagens com finalidades culturais. O texto dava o título do vídeo e deixava clara a possibilidade de sua exibição (não comercial) em contextos acadêmicos, nacionais ou mesmo internacionais. Referia também sua utilização em sala de aula ou palestras.

\footnotetext{
${ }^{33}$ Nestes casos, a participação de estudantes moradores mostrou-se fundamental, uma vez que eram conhecidos diretos dos funcionários da prefeitura (ou por relações familiares ou de amizade pregressa).

${ }^{34}$ Éramos um grupo formado por mim e outros três estudantes que atuaram como assistentes de câmera e produção: Danilo Alex, Luana Maia e Jaquisandro Ferreira.

${ }^{35}$ As quais foram também captadas de outras posições (previstas) durante o percurso de rua que levava até defronte ao palanque.
} 
Ao final do texto anunciava-se o compromisso do diretor do filme quanto a entregar dois exemplares do filme para cada escola envolvida no desfile. Nesse ponto o funcionário da prefeitura colocou uma objeção, a saber, de que a prefeitura já tinha esgotado seus recursos para a área cultural naquele ano e que não havia nenhuma condição de financiar os DVDs. Após esclarecimentos ${ }^{36}$ sobre o texto da autorização, uma vez que não se pedia apoio da prefeitura, mas apenas autorização quanto ao uso das imagens tomadas em um evento municipal, foi concedida a assinatura do termo pelo setor responsável.

Nas relações diversas estabelecidas, portanto, com os diferentes participantes colaboradores no filme ${ }^{37}$ ou com funcionários da prefeitura, torna-se possível vislumbrar diferentes “campos semânticos em interação dialógica”? (Oliveira, 2006: 180). Como assegurar, neste contexto marcado também pelas clivagens pertinentes às tradições oral e escrita (ou mesmo à etnicidade), melhores condições para uma "comunicação não distorcida" (Ibid.)? O trabalho com imagens na perspectiva de constituição de uma memória visual coletiva atua no sentido de exercitar e favorecer uma comunicação concebida como articulação possível entre as diferentes esferas (micro-meso-macro) da ética?

O trabalho feito com as imagens a partir da universidade, motivado pelas discussões éticas oriundas do campo da antropologia (visual), interfere, pois, no campo das relações face a face locais e introduz novas modalidades de circulação e de ressignificação destas imagens ${ }^{38}$. Se por um lado tende a reconhecer as distâncias entre diferentes campos semânticos em interação (nas relações estabelecidas durante a pesquisa), consequentemente contribui para o questionamento dos discursos locais "naturalmente" associados a estas imagens, na medida em que procura articular vozes diversas, independentemente de ocuparem ou não um lugar de autoridade.

Fica entrevisto, nesse caminho, o fato de que a pesquisa fotográfica no campo da antropologia visual abre diferentes possibilidades de interpretação e de relações intersubjetivas, as quais tendem a ampliar o legado que as fotografias nos desafiam a descobrir. Essa ampliação implica também ouvir sujeitos que não escrevem (no papel

\footnotetext{
${ }^{36}$ Mais uma vez a participação dos estudantes moradores (neste caso, de Danilo Alex Marques de Farias) foi imprescindível para intermediar a obtenção da autorização.

${ }^{37}$ No caso dos participantes do filme, desde o início tratou-se de relações face a face (ao nível da oralidade).

${ }^{38}$ As concepções locais sobre a natureza das fotografias e as condições de sua circulação são restringidas por diversos fatores. Na pesquisa antropológica com imagens outras concepções e condições são praticadas e tendem a ser mais ou menos incorporadas na esfera das relações face a face, abrindo novas possibilidades de significação e de circulação a partir das esferas meso e macro-éticas.
} 
nem por teclados de computadores), mas, que vêem e falam. A atenção às expressões de oralidade em suas diferentes dimensões se faz necessária, portanto, na discussão da ética de uso de imagens na pesquisa fotográfica. As experiências relatadas e as questões levantadas que ficaram em aberto devem motivar a posterior retomada destas reflexões.

\section{Referências}

BANKS, M. Dados visuais para pesquisa qualitativa. Porto Alegre: Artmed, 2009. CALVET, Louis-Jean. Tradição oral \& tradição escrita. São Paulo: Parábola, 2011. COLLIER Jr., John. Antropologia Visual: a fotografia como método de pesquisa. São Paulo: EPU-EdUSP, 1973.

COLLOMB, Gerard. "Imagem do outro, imagem de si." In: Cadernos de Antropologia e Imagem, n.6 (1). Rio de Janeiro: UERJ/Contra-capa, 1998. p. 65-80.

ECKERT, C. e ROCHA, A. L. C. "Antropologia visual em suas aprendizagens: pesquisa, ensino e questões éticas".In: Revista Iluminuras, v.5, n.11. Porto Alegre: BIEV/ UFRGS, 2004. Disponível em: < http://seer.ufrgs.br/iluminuras/issue/view/768>. Acesso em 10 de maio de 2012.

"Imagem recolocada: pensar a imagem como instrumento de pesquisa e análise do pensamento coletivo". In: Revista Iluminuras, n.3. Porto Alegre: BIEV/ UFRGS, 2001. Disponível em: <http://www.iluminuras.ufrgs.br>. Acesso em 23 de abril de 2009.

FLUSSER, Vilém. A filosofia da caixa-preta. Ensaios para uma futura filosofia da fotografia. São Paulo: Hucitec, 1985.

. O universo das imagens técnicas. São Paulo: Annablume, 2008.

GONÇALVES, J. R. S.. "Coleções, museus e teorias antropológicas: reflexões sobre conhecimento etnográfico e visualidade". In: Cadernos de Antropologia e Imagem, n.8(1) Rio de Janeiro: NAI/UERJ, 1999. p. 21-34.

GONÇALVES, Regina Célia. Guerras e Açúcares. Política e economia da Capitania da Parayba 1585 - 1630. Baurú: Edusc, 2007.

HOUAISS, Antonio. As projeções da língua árabe na língua portuguesa. Disponível em < http://www.hottopos.com/collat7/houaiss.htm $>$. Acesso em 26 de fevereiro de 2012.

KOSSOY, B. Fotografia e História. (2a ed. rev.). São Paulo: Ateliê Editorial, 2001. . Dicionário histórico-fotográfico brasileiro: fotógrafos e ofício da fotografia no Brasil (1833-1910). São Paulo: Instituto Moreira Sales, 2002.

LEITE, M. M. Retratos de família: leitura da fotografia histórica. São Paulo: FAPESP/EDUSP, 1993.

LIMA, José Fernandes de. A lealdade e o heroísmo do índio Potiguara Pedro Poty. João Pessoa: A União, 1990.

LIRA, B. de S. Fotografia na Paraíba: um inventário dos fotógrafos através do retrato (1850 a 1950). João Pessoa: SEC/Editora Universitária, 1997.

MENDONÇA, João Martinho de. "Entre fotografias antigas e redes sociais: trajetórias de pesquisa fotográfica no interior de Minas Gerais e da Paraíba". In: Revista Iluminuras, v.12, n.28, jul/dec. Porto Alegre: BIEV/ UFRGS, 2011. p. 70-102. 
MOONEN, F. e MAIA, Luciano M. (Orgs.) Etnohistória dos Índios Potiguara. João Pessoa: Procuradoria da República na Paraíba/ Secretaria da Educação e Cultura do Estado da Paraíba, 1992.

OLIVEIRA, Roberto Cardoso. O trabalho do antropólogo. Brasília/ São Paulo: Paralelo 15/Unesp, 2006.

PANET, A. et al. Rio Tinto: estrutura urbana, trabalho e cotidiano. João Pessoa: UNIPÊ, 2002.

PORTO, Maria das Dores e LAGE, Iveline L. C. CEPLAR: História de um sonho coletivo. Uma experiência de educação popular na Paraíba destruída pelo golpe de estado de 1964. João Pessoa: SEC, 1995.

RECHENBERG, Fernanda. Imagens e trajetos revelados: estudo antropológico sobre fotografia, memória e a circulação das imagens junto a famílias negras em Porto Alegre, RS. 2012. Tese de Doutoramento - PPGAS - Universidade Federal do Rio Grande do Sul, Porto Alegre, 2012.

SAMAIN, Etienne. "Oralidade, Escrita, Visualidade. Meios e Modos de Construção dos Indivíduos e das Sociedades Humanas". In: Soc. Bras. de Psicanálise de S.P. (org.) Perturbador Mundo Novo. História, Psicanálise e Sociedade Contemporânea. 1492 1900 - 1992. São Paulo: Escuta, 1994. p. 289-301.

SCHERER, Joanna. "Documento fotográfico: fotografias como dado primário na pesquisa antropológica". In: Cadernos de Antropologia e Imagem, n.3. Rio de Janeiro: NAI/UERJ, 1996. p. 69-83.

SIMSON, O. R. de M. Carnaval em branco e negro: carnaval popular paulistano: 1914-1988. Campinas: Unicamp/ São Paulo: Edusp/ Imprensa Oficial, 2007.

Recebido em: 31/10/2012

Aprovado em: 15/12/2012 